\title{
Percursos da constituição de UMa POlítica brasileira de EDUCAÇÃo ESPECIAL INCLUSIVA ${ }^{1}$ \\ INSTITUTION COURSE OF A BRAZILIAN SPECIAL EDUCATION INCLUSIVE POLICY
}

\author{
Mônica de Carvalho Magalhães KASSAR ${ }^{2}$
}

\begin{abstract}
RESUMO: este artigo propõe-se a apresentar análises de alguns elementos que contribuem para a constituição da Educação Especial brasileira como uma política pública, dando especial foco à formulação do que tem sido denominada de política de educação especial na perspectiva inclusiva ou educação inclusiva. Para tanto, o texto é construído a partir da configuração de dois aspectos distintos, mas intimamente interligados. O primeiro referese ao papel do Governo brasileiro na história da educação destinada às pessoas com deficiências no Brasil. $\mathrm{O}$ segundo diz respeito às relações entre as políticas nacionais no campo da Educação e os acordos e compromissos internacionais. Conclui ressaltando a importância dos diferentes setores da sociedade nos embates atuais para a formulação de uma política de educação brasileira, que incorpore, de fato, toda a população.
\end{abstract}

PALAVRAS-CHAVE: Política Educacional. Educação Especial. Educação Inclusiva. ANPEd.

\begin{abstract}
This article proposes to present an analysis of some elements that contribute to a construction of Special Education as a public policy, emphasizing the formulation of what has been nominated special education inclusive perspective or inclusive education policy. For this, this text is structured considering two interrelated distinct aspects. The first refers to the Brazilian Government role in the history of education for disabled people in Brazil. The second is regarded the relationship between national policies in the education field and international agreements. The conclusion highlights the importance of involving different sectors of the society in the struggles for the development of a Brazilian educational policy that actually incorporates the entire population.
\end{abstract}

KEYWORDS: Educational Policy. Special Education. Inclusive Education. National Association of PostGraduation and Research.

\section{INTRODUÇÃO}

Este artigo tem por objetivo apresentar análises de alguns elementos que contribuem para a constituição da educação especial brasileira como uma política pública, enfocando especialmente as proposições que compõem o que tem se denominado de política de educação especial na perspectiva inclusiva ou educação inclusiva. Entendo que políticas, programas e ações referem-se ao sistema de proteção social de um país. Entendo também que essa política vem sendo formatada ao longo das últimas décadas, como possível síntese de embates de forças sociais e econômicas. Tentando dar forma a esse percurso, o texto é construído considerando a configuração de dois aspectos distintos, mas interligados. O primeiro referese ao papel do Governo brasileiro na história da educação destinada às pessoas com deficiências no Brasil. O segundo diz respeito às relações entre as políticas nacionais no campo da Educação e os acordos e compromissos internacionais.

${ }^{1}$ Este trabalho é resultante de estudos elaborados na pesquisa Educação Inclusiva: Proposta Política e Cotidiano Escolar, apoiada pelo CNPq e no plano de estágio pós-doutoral Educação para pessoas com deficiências: Direito Humano e Política Pública, realizado no Departamento de Ciência Política, na UNICAMP.

${ }^{2}$ Docente da Universidade Federal de Mato Grosso do Sul - UFMS. Contato: mkassar@terra.com.br. 
KASSAR, M. C. M.

Di Giovanni (2009) entende a política pública como uma "forma contemporânea de exercício do poder nas sociedades democráticas, resultante de uma complexa interação entre o Estado e a sociedade, entendida aqui num sentido amplo, que inclui as relações sociais travadas também no campo da economia" (p.4-5). Essa conceituação, segundo o autor,

[...] depende, por sua vez, da concretização histórica de alguns requisitos que configuram as modernas democracias: pressupõe-se uma capacidade mínima de planificação consolidada nos aparelhos de Estado, seja do ponto de vista técnico de gestão, seja do ponto de vista político. Pressupõe-se, também, certa estruturação republicana da ordem política vigente: coexistência e independência de poderes e vigência de direitos de cidadania; e, pressupõe-se, finalmente, alguma capacidade coletiva de formulação de agendas públicas, em outras palavras, o exercício pleno da cidadania e uma cultura política compatível. (DI GIOVANNI, 2009, p 5).

Portanto, por essa concepção, pode-se considerar que as políticas públicas brasileiras tendem a amadurecer com o fortalecimento da democracia, pósConstituição de 1988, de modo que o estado brasileiro possa ser visto

[...] não apenas como aquele que inclui mecanismos clássicos de representação (direito de votar e ser votado; participação igualitária de classes, categorias e interesses), mas também aquele que revela uma forte capacidade de resposta (responsiveness) às demandas da sociedade (Op. cit., p.15)

A Educação Especial nas últimas décadas tem ganhado contorno de política pública constituída por embates entre diversos setores da sociedade e das instâncias governamentais, afetada, muitas vezes, por determinações originariamente externas ao país. São estes aspectos que pretendo ressaltar.

\section{O ESTADo bRASILEIRO E A EDUCAÇÃo DESTINADA ÀS PESSOAS COM DEFICIÊNCIAS NO BRASIL}

Como tem sido afirmado por Jannuzzi (1984, 2004), Mazzotta (1996) Bueno (2004), Ferreira (1993), entre outros, o conhecimento e a análise da educação direcionada às pessoas com deficiências só podem ser entendidos quando percebidos dentro da história da educação e por sua vez, dentro da história em geral de um determinado país. O próprio movimento pela ampliação do acesso à escola de pessoas com deficiência, hoje, ocorre no movimento de universalização da educação fundamental brasileira.

A relação entre fatores específicos e gerais está evidente no decorrer de nossa história. No início da República, os primeiros sinais de atenção às pessoas com deficiências no Brasil apareceram sob impacto de idéias já difundidas na Europa comungadas por estudiosos daqui. A atenção sobre o que foi considerado "anormal" pode ser identificada na literatura médica da época ${ }^{3}$ e na legislação

\footnotetext{
3 Duas obras são identificadas por Rocha (1979) como fundamentais para a educação dos "anormais" nesse momento: Educação da Inteligência Anormal no Brasil, de Clemente Quaglio e Tratamento e educação das crianças anormais de inteligência, de Basílio de Magalhães, ambas dos anos de 1910
} 
educacional que restringia a essa população o acesso à escolarização ou à instrução, como era tratada a Educação no período. Decretos de diferentes estados atestam essa posição, como o decreto-lei 7970 de 1927 de Minas Gerais que dispensa de freqüência às aulas, entre outros motivos, crianças com "incapacidade física ou mental" e indigentes, "enquanto não se fornecer, pelos meios de assistência [...], o vestuário indispensável à decência e à higiene" (apud PEIXOTO, 1981).

O estado de São Paulo, por meio do Decreto 5.884, quando normatizou sua "Educação Especializada", entendeu como parte de seu alunado os "débeis físicos", "débeis mentais", "doentes contagiosos", "cegos", "surdos-mudos" e os "delinqüentes" (BRASIL, 1933). A formação de um grupo de "anormais", para a época, era utilizada seja para seu impedimento de freqüência à escola, seja para atenção de uma educação especializada, preferencialmente em escolas especializadas ${ }^{4}$. Muitos estados implantaram serviços de higiene para identificação de crianças anormais e instituição de salas de aulas homogêneas, consideradas à época como mais produtivas. A restrição explícita à instrução para parte específica da população brasileira (crianças com deficiências e crianças sem vestimentas ou costumes "adequados") é apenas um aspecto dos problemas educacionais brasileiros, visto que o país possuía um alto índice de pessoas analfabetas ${ }^{5}$. Alguns aspectos explicam essa situação. A organização econômica do Brasil Colônia e do Brasil Império não solicitava a alfabetização e a instrução da massa trabalhadora, visto que grande parcela da população vivia na zona rural e a economia baseavase, inicialmente, na exploração de bens naturais e, posteriormente, na produção de monoculturas em grandes latifúndios. Um segundo aspecto a ser ressaltado é que em Portugal, colonizador do Brasil, conforme mostram os registros ${ }^{6}$ do século XIX, grande parte da população não tinha acesso à instrução e era analfabeta. Ainda, apesar de a educação ser prevista para "todos os cidadãos" desde a $1^{\text {a }}$ Constituição brasileira, em 1824, a massa de trabalhadores era composta de maioria escrava ${ }^{7}$. Portanto, a restrição à educação é constitutiva da história do Brasil.

Com a industrialização, no decorrer do século XX, o deficitário acesso à escolaridade continuou a ser um problema nacional. Mesmo com a paulatina mudança da distribuição geográfica brasileira, com o crescimento dos centros urbanos, as crianças das camadas operárias estiveram presentes nas fábricas ${ }^{8}$, mas quase ausentes nas escolas. Até a década de 1960, a taxa de escolarização obrigatória brasileira estava longe da universalização, apesar de ser, na época, apenas de quatro anos. Um relatório da UNESCO, datado de 1963, afirma que

${ }^{4}$ O Art. 834 desse decreto indicava preferência pela organização de escolas especializadas, sugerindo a formação de classes para esses fins, quando não houvesse a existência das escolas.

${ }^{5}$ Schwarcz (1998 apud VEIGA, 2008) informa que um recenseamento do final do século XIX registrou que 84\% da população brasileira eram constituídos de analfabetos e dados posteriores, referentes ao Brasil República, apresentados por Ribeiro (1978) mostram a contínua escassez de escolarização no país.

${ }^{6}$ Informações registradas por Costa (1868) in Antologia de textos pedagógicos do século XIX português. Vol. III. Lisboa: Instituto Gulbenkian de Ciência, 1975, p. 179.

${ }^{7}$ Segundo Basbaum (1982), em meados do século XIX, praticamente 1/3 da população brasileira era escrava.

${ }^{8}$ Para conhecimento deste aspecto, ver Moura (1991). 
enquanto muitos países europeus atingiam a universalização do ensino obrigatório e registravam grande expansão do ensino de $2^{\circ}$ grau, outros (entre eles, o nosso) ainda não haviam conseguido "escolarizar mais do que a minoria das crianças em idade de freqüentar a escola primária" e estavam "longe de haver ensinado toda a população a ler e escrever" (apud UNESCO, 1982, p. 11). A mesma avaliação é feita pelo próprio Ministério da Educação e Cultura uma década depois:

A universalização da escola fundamental, para a população de 7 a 14 anos, apesar de preceito constitucional, ainda está longe de ser alcançada no Brasil. $\mathrm{O}$ não cumprimento da obrigatoriedade escolar conduz ao desperdício de milhões de cérebros, espíritos e vontades, extremamente necessários ao País, mas que, marginalizados do processo educacional, pouca contribuição podem dar à sociedade, além de disporem de oportunidades reduzidíssimas de ascensão na escala econômica e social. Por isso, o preceito constitucional é sábio e seu cumprimento deve ser perseguido tenazmente. (BRASIL, 1975, p.2).

Os trechos pinçados de nossa história tratam de aspectos a serem considerados para o entendimento da formulação de uma política educacional brasileira. Pelas características de nossa educação, a atenção direcionada para pessoas com deficiência (Educação Especial) deu-se, em grande medida, pela ação de um conjunto de instituições privadas de caráter assistencial, não considerado pertencente à rede de ensino brasileira.

A Lei de Diretrizese Bases de1961 reconhece a educação dos "excepcionais" quando indica sua matrícula "dentro do possível" na rede regular de ensino, mas ao mesmo tempo garante apoio financeiro às instituições especializadas. Chama a atenção a proposição da matrícula na rede regular para alunos que, cerca de trinta anos antes, eram dispensados da escola. A adesão do país a acordos internacionais pós-1948 pode ser considerada impulsionadora dessa ação, além dos movimentos internos de luta pela educação das pessoas com deficiências e a disseminação de preceitos da Escola Nova9 . A Convenção relativa à Luta contra a Discriminação no campo do Ensino, adotada pela conferência geral da UNESCO em 1960, traz pressupostos importantes adotados formalmente no Brasil ${ }^{10}$. Para a Convenção, o termo "discriminação"

[...] abarca qualquer distinção, exclusão, limitação ou preferência que, por motivo de raça, cor, sexo, língua, religião, opinião pública ou qualquer outra opinião, origem nacional ou social, condição econômica ou nascimento, tenha por objeto ou efeito destruir ou alterar a igualdade de tratamento em matéria de ensino, e, principalmente: a) privar qualquer pessoa ou grupo de pessoas do acesso aos diversos tipos ou graus de ensino; b) limitar a nível inferior à educação de qualquer pessoa ou grupo; c) sob reserva do disposto no artigo 2 da presente Convenção, instituir ou manter sistemas ou estabelecimentos de ensino separados para pessoas

\footnotetext{
${ }^{9}$ Lourenço Filho, em obra de 1929, explica que a Escola Nova refere-se a um "conjunto de princípios tendentes a rever as formas tradicionais de ensino" (p. 17). Esse movimento proporcionou atenção especial ao desenvolvimento da criança e levou à experimentação de novos procedimentos de ensino.

${ }_{10}$ O Decreto ${ }^{\circ}$ 63.223, de 6 de setembro de 1968, determina que a Convenção seja executada e cumprida. Assina o documento, o então Presidente da República Artur da Costa e Silva.
} 
ou grupos de pessoas; ou d) de impor a qualquer pessoa ou grupo de pessoas condições incompatíveis com a dignidade do homem (UNESCO, 2003).

Em 1967, a primeira Constituição após o Golpe de Estado de 1964 previu o estabelecimento dos planos nacionais de educação. A Emenda Constitucional de 1969 estabeleceu a execução dos planos nacionais e regionais de desenvolvimento. A legislação sobre as diretrizes e bases da educação nacional foi revista e, em 1971, a Lei Educacional n 5.692 passou a obrigatoriedade da escolarização brasileira para oito anos. Esse período foi decisivo para o início da formatação da Educação Especial como uma política de estado, com a criação de um órgão vinculado ao Ministério da Educação e Cultura, o Centro Nacional de Educação Especial (CENESP), que passou a ter a responsabilidade de formular e impulsionar as ações de Educação Especial no Brasil. A criação deste órgão e a implantação de suas ações encontraram subsídio na perspectiva desenvolvimentista adotada pelo regime militar à época. Para a sua concepção, foram convidados como assessores técnicos os professores James J. Gallagher, da Universidade de Carolina do Norte e David M. Jackson, da Superintendência da Educação Pública em Springfield, Illinois, ambos dos Estados Unidos da América ${ }^{11}$. A Educação Especial a ser implantada no país tinha como fundamentos a teoria do Capital Humano e os princípios de normalização e integração, estes últimos difundidos desde o final da década de 1950. O presidente da República era Ernesto Garrastazu Médici e o discurso corrente sobre a educação era de investimento para a formação de recursos humanos e para o desenvolvimento do país (JANNUZZI, 2004). Gallagher (1974) defendia que:

[...] um retardado e internado entre as idades de 10 e 60 anos, nos Estados Unidos, para ser cuidado, custa ao Estado US\$ 5.000 ao ano, ou um total de US\$250.000 durante toda a sua vida. O mesmo indivíduo recebendo educação e tratamento adequados pode tornar uma pessoa útil e contribuir para a sociedade. Assim, o custo extra que representam os custos extras com educação especial pode ser compensador quanto a benefícios econômicos maiores. Há um estudo segundo o qual um adulto retardado e educado poderia ganhar US\$ 40 para cada dólar extra despendido com sua educação. (p. 100)

O trecho acima apresenta a incorporação da Teoria do Capital Humano na educação especial, coerente ao restante do discurso educacional brasileiro (c.f. SAVIANI, 2008). Indica, também, que como todo o ideário desenvolvimentista, a implantação de tais serviços pautou-se, ao menos em parte, na sua função econômica (ARRUDA; KASSAR; SANTOS, 2006).

A consideração da Educação Especial como foco de política de estado, no entanto, não dispensou, em qualquer momento, a contribuição decisiva do setor privado. Em 1976, o II Plano Setorial da Educação e Cultura entendia que a Educação Especial representava “o resultado da ação conjugada dos poderes

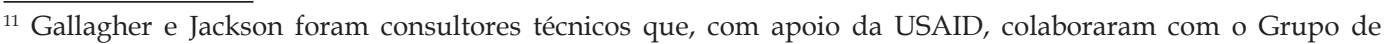
trabalho do Ministério da Educação e Cultura encarregado da montagem do Projeto Prioritário $\mathrm{n}^{\circ} 35$ do Plano Setorial de Educação e Cultura do MEC, em 1972 (PIRES, 1974).
} 
KASSAR, M. C. M.

públicos e da iniciativa particular" (p.23). Na época, tal plano tinha como objetivo geral para o setor: "Assegurar igualdade de oportunidades aos educandos que apresentam condições especiais de desenvolvimento biopsicológico ou físico." (p.37) e foram propostos:

“1. habilitar o pessoal docente e técnico necessário ao atendimento de portadores de deficiências físicas ou mentais, bem como dos superdotados; 2. treinar o pessoal docente das escolas regulares que devam receber, para integração, os alunos subdotados". (BRASIL, 1976, p.56).

Apesar dos esforços para expansão da educação pública, um relatório elaborado pelo Ministério da Educação e Cultura que avaliou a efetividade da escola brasileira na década de 1970 mostrou que "apenas 13,8\% dos que iniciaram a $1^{\text {a }}$ série em 1972 conseguiram terminar a $8^{\mathrm{a}}$ serie em 1979". (BRASIL, s/d). É nesse contexto escolar que a Educação Especial foi aos poucos tomando corpo como ação do poder público, de modo que durante essa década diversas classes especiais foram implantadas em todo o país, sendo que o setor público chegou a atender 97,8 \% dos alunos em situação de "integração", ou seja, matriculados em estabelecimentos de ensino regular no início dos anos de 1980 (BRASIL, 1984). No entanto, até finais da década de 1980, o setor público atendeu, em sua maioria, alunos com deficiências leves e muitos repetentes, oriundos da ineficaz escola brasileira descrita no relatório acima, em classes especiais. Os alunos que demandavam atendimento mais especializado continuaram sendo assumidos pelo setor privado, nas instituições especiais assistenciais ${ }^{12}$.

\section{Políticas Nacionais E OS ACORdos InTERnaCionais ${ }^{13}$}

A partir da Constituição Federal de1988, a Educação passa a ser apresentada como um Direito Social, de modo que o Capítulo II, relativo aos Direitos Sociais, tem em sua atual redação a determinação: "Art. $6^{\circ}$ São direitos sociais a educação, a saúde, a alimentação, o trabalho, a moradia, o lazer, a segurança, a previdência social, a proteção à maternidade e à infância, a assistência aos desamparados, na forma desta Constituição" (redação dada pela Emenda Constitucional n ${ }^{\circ}$ 64, de 2010). A partir da aprovação dessa Carta, ocorre a universalização da Educação e também da Saúde (através do Sistema Único de Saúde - SUS), e estabelecese a abrangência do sistema de proteção social aos cidadãos, independente de contribuição. Portanto, a política educacional passa, a partir de 1988, a ser uma política pública de caráter universal e isso gera mudanças no sistema de ensino.

\footnotetext{
${ }^{12}$ Em levantamento realizado em 1988, o Ministério da Educação mostrou que, dos alunos que recebiam atendimento especializado no Brasil, 21,78\% estavam em instituições sob administração pública e 78,21\% em instituições privadas (BRASIL, 1991a; 1991b). Pelo aspecto de complementaridade entre os setores público e privado, no que se refere ao atendimento de alunos com deficiências, Jannuzzi (1997) entende trata-se de uma "parcial simbiose".

${ }^{13}$ Uma abordagem inicial desta temática foi apresentada no IV Congresso Brasileiro de Educação Especial, UFSCar, 2010, sob o título "Política de educação especial no Brasil: escolha de caminhos".
} 
No mesmo período em que se consolida o sistema de proteção social, estabelecido pela Constituição Federal de 1988, inicia-se a disseminação de uma proposta Educação Escolar Inclusiva. A disseminação das idéias acerca da Educação Inclusiva pode ser atribuída, ao menos, a três aspectos. O primeiro referese a mudanças importantes ocorridas pelo mundo, relativas ao atendimento das pessoas com deficiências. No final da II Guerra Mundial, houve uma preocupação com as pessoas que adquiriram deficiências em decorrência dos conflitos bélicos, de modo que a Organização Internacional do Trabalho $(\mathrm{OIT})^{14}$ apresentou, nesse período, entre suas preocupações a garantia de emprego para os mutilados de guerra e indenizações. Essa atenção é compartilhada por diferentes países. Nesse período, o dinamarquês Bank-Mikkelsen, advogado e ex-prisioneiro de campo de concentração ${ }^{15}$, desenvolve idéias que contêm o princípio de normalização e o introduz na legislação de seu país em 1959 através do Mental Retardation Act. Quase dez anos depois, o sueco Bengt Nirje formaliza o princípio de Normalização e o publica (NIRJE, 1999). Na década de 1970, os Estados Unidos da América aprovaram o IDEA - Individuals with Disabilities Act. 1977/1978 (MENDES, 2006; BAYER, 2006) e na Inglaterra o relatório sobre necessidades especiais (Special Needs Report ou Relatório Warnock) foi divulgado em 1978 (LAPLANE, 2006, 2010). Ainda, vários países registraram experiências de matrículas de crianças com deficiências em salas de aulas comuns: na Alemanha e nos Estados Unidos da América, nos anos 1970; na Espanha nos anos 1980. (c.f. BAYER, 2006; ORTIZ GONZALEZ, 2005; entre outros).

O segundo aspecto refere-se ao movimento de pessoas com deficiências ou de pais e profissionais ligados a elas que, principalmente a partir da década de 1950, organizam-se em associações em defesa de seus direitos (JANNUZZI, 2004). Essas instituições passaram a se internacionalizar, articulando-se através de redes de informação e de colaboração, com a formação de ligas, congressos, associações, entre outros.

O terceiro aspecto refere-se às convenções internacionais que são aceitas e ratificadas pelo Brasil. A relação entre a política pública brasileira (e não apenas a política educacional) e esses acordos, especialmente após a reorganização por que passou o país nos anos 90 do século XX (Reforma de Estado), diz respeito ao processo de internacionalização da economia, que conta com a participação direta de proposições estabelecidas com instituições financeiras internacionais ${ }^{16}$. Nesse

\footnotetext{
${ }^{14}$ Este órgão foi incorporado à Organização das Nações Unidas (ONU) nesse período.

${ }_{15}$ Bank-Mikkelsen foi prisioneiro em um campo de concentração nazista e desenvolveu idéias que derem origem ao conceito de normalização a partir da percepção que a pessoas com deficiências institucionalizadas eram tratadas melhor apenas do que os prisioneiros de campo de concentração. Para detalhes ver http://www. sagepub.com/upm-data/5901_Entries_Beginning_with_B_Albrecht_Rev_I_Proof.pdf.

${ }^{16}$ São fundos e agências especializadas da Organização das Nações Unidas (ONU): o BIRD, Banco Internacional para a Reconstrução e o Desenvolvimento (ou Banco Mundial), o Fundo Monetário Internacional, a Organização Internacional do Trabalho (OIT), Organização Mundial do Comércio (OMC), Comissão Econômica para a América Latina e o Caribe (CEPAL), Organização Mundial da Saúde (OMS), Organização das Nações Unidas para Educação, Ciência e Cultura (UNESCO). Para maior conhecimento, ver http:/ / www.onu-brasil.org.br/
} 
processo, as nações têm suas ações reguladas - em certa medida - pelas agências multilaterais. Como analisa Koerner,

O processo de internacionalização da economia limitou a capacidade de regulação por parte dos Estados e aprofundou as trocas econômicas entre as sociedades nacionais, tornando mais candentes questões relativas à regulamentação dos investimentos externos e do comércio, à regulação dos fluxos de capitais e à adoção de salvaguardas e medidas compensatórias em favor das sociedades mais empobrecidas. Assim, nesse contexto tornaram-se decisivas a organização de instâncias de coordenação econômica (OMC) e a atribuição de um papel ampliado para agências financeiras, como o Banco Mundial (2003, p.144).

A citação acima possibilita esclarecer as ligações entre o Banco Mundial e as conferências no campo social. Draibe e Riesco (2006) afirmam que as teorias econômicas que defendem a tese de que a política social é condição do desenvolvimento econômico, formulada há mais de quarenta anos, tem sido estimulada pela Organização das Nações Unidas (ONU) e recentemente sido fortalecida pelos princípios dos diretos humanos, com os conceitos de desenvolvimento humano e coesão social. Desde o início da década de 1990, este princípio integrado (desenvolvimento - economia) tem servido de referência a outros órgãos multilaterais. Portanto, agências, como o Banco Mundial, além de presentes no direcionamento de políticas econômicas, também marcam forte presença nos debates sociais. A atenção do Banco Mundial à área social responde, de certa forma, a questões sociais demandadas por organizações da sociedade civil.

[...] as organizações da sociedade civil trouxeram para o primeiro plano questões já presentes nos fóruns internacionais, como políticas ambientais para o desenvolvimento sustentável, contra a fome e em favor de setores sociais ou minorias em situação de risco nas diversas partes do mundo. (KOERNER, 2003, p. 144)

Os aspectos apresentados no início deste tópico, presentes na disseminação da Educação Inclusiva (experiência de diferentes países - movimento da sociedade civil - acordos internacionais), se entrelaçam. As conferências internacionais encontram adesão da sociedade civil, pois respondem, de certa forma, às suas demandas. Ao mesmo tempo, a disseminação de ideias pelas conferências impacta os países e suas proposições internas.

As Nações Unidas adotaram uma agenda de tratamento das questões globais em foros multilaterais, cujo objetivo principal é a adoção de princípios e planos de ação que orientem a solução daquelas questões. Dessa iniciativa resultaram as conferências das Nações Unidas sobre temas sociais da década de 1990. (Idem, p. 144)

As políticas e ações adotadas pelo Brasil desde a década de 1990 devem ser entendidas na consideração do panorama apresentado acima. Como exemplo, cito a organização da Conferência Mundial de Educação para Todos, de 1990, promovida pela UNESCO e pelo Banco Mundial. Outro exemplo refere-se diretamente à Educação Especial. Um documento elaborado em 1999, para avaliar 
as metas propostas pela Declaração de Salamanca (1994), explicita a intenção da UNESCO em disseminar ideias que direcionem os países na elaboração de políticas coerentes às suas proposições:

La UNESCO ha asumido un rol catalizador a la hora de compartir y difundir nuevas formas de pensar y nuevas prácticas para integrar las necesidades educativas especiales dentro del sistema de educación regular. Los principales esfuerzos de U N E S C O se han centrado en:

- desarrollar las capacidades nacionales para la formulación de políticas y la administración del sistema en apoyo a la educación inclusiva, y

- recoger las preocupaciones de las personas con discapacidad, al igual que otros grupos marginados, en una agenda educativa más amplia y en las agendas de organizaciones internacionales para el desarrollo. (UNESCO, 1999).

Cabe, aqui, uma análise da participação da UNESCO nos diferentes países, como agência fomentadora de públicas nas áreas da Educação, Ciência e Cultura. Além de desenvolver as capacidades nacionais para formulação de políticas de Educação nos países, Finnemore (1993), a partir da realização de um estudo, argumenta que a UNESCO tem a missão de ensinar às nações que o controle e o direcionamento da ciência são tarefas dos Estados Modernos, daí a necessidade de formação de organizações burocráticas para este fim. Dessa forma, os Estados criam, com auxílio da UNESCO, tais setores e as demandas de pesquisa vêm muito mais de fora do país, do que de questões internas a eles.

As relações entre os países e a internacionalização da economia são perpassadas por muitos aspectos. Dale (2004), ao analisar estudos que abordam a relação globalização - educação, identifica a existência de dois enfoques. $O$ primeiro, ele denomina de Cultura Educacional Mundial Comum. Nesse grupo, estão estudos desenvolvidos principalmente por John Meyer e seus colaborados da Universidade de Stanford (Califórnia). A tese principal poderia ser assim resumida: "o desenvolvimento dos sistemas educativos nacionais e as categorias curriculares se explicam através de modelos universais de educação, de estado e de sociedade, mais do que através de factores nacionais distintivos" (p.425). Ou seja,

[...] as instituições do estado-nação, e o próprio estado, devem ser vistos como sendo essencialmente moldados a um nível supranacional através de uma ideologia do mundo dominante (ou Ocidente), e não como criações nacionais autónomas e únicas. Sob esta perspectiva, os estados têm a sua actividade e as suas políticas moldadas por normas e cultura universais (p. 426 - 427).

Assim, haveria a formação de uma cultura comum. O autor esclarece que, para essa abordagem,

"longe de serem autonomamente construídas a um nível nacional, as políticas nacionais [de educação] são em essência pouco mais do que interpretações de versões ou guiões que são informados por, e recebem a sua legitimação de ideologias, valores e culturas de nível mundial" (p.429). 
KASSAR, M. C. M.

Dessa forma, “A educação de massas, no período moderno, não só tem sido altamente valorizada como também tem sido vista como um método científico ou racionalizado de produzir progresso social" (MEYER; KAMENS, 1992 apud DALE, 2004, p. 433 - 434). A educação nos países teria, então, a função de formar cidadãos modernos.

O outro grupo é denominado Agenda Globalmente Estruturada para a Educação e refere-se a pesquisas desenvolvidas pelo próprio Dale (2004). Esta perspectiva entende que os sistemas educativos dos países sofrem impactos/ efeitos de agendas internacionais (ainda que mediados pela organização local), com objetivo final de manutenção do sistema de produção capitalista. Por esse enfoque, a manutenção da economia capitalista é a fonte decisória das políticas educacionais. Este argumento fica mais claro nas palavras de Dale (2004):

\begin{abstract}
As agendas nacionais para a educação são formadas mais no nível do regime do que no nível estrutural; [...] todos os quadros regulatórios nacionais são agora, em maior ou menor medida, moldados e delimitados por forças supranacionais, assim como por forças político-económicas nacionais. E é por estas vias indirectas, através da influência sobre o estado e sobre o modo de regulação, que a globalização tem os seus mais óbvios e importantes efeitos sobre os sistemas educativos nacionais (p. 441).
\end{abstract}

Apesar da distinção entre as duas abordagens analisadas por Dale, é inegável o aspecto comum que é o reconhecimento de que há uma relação íntima entre as políticas educacionais dos diferentes países e o processo de globalização. Essa relação fortalece-se em várias frentes e, entre elas, através das agências multinacionais que direcionam ações através de suas declarações, seus acordos e convênios multilaterais. Os trabalhos que abordam a relação entre a formulação das políticas educacionais e os interesses globais fornecem elementos adicionais para se entender a educação no Brasil. Pois, além de ser concebida como um "Direito Social", a educação é também valorizada como formadora de uma "cultura da modernidade" e/ou como foco importante para o desenvolvimento do capitalismo.

Esses aspectos também devem ser considerados quando se aborda o tema da Educação inclusiva no Brasil. O período em que se inicia a disseminação do discurso sobre Educação Inclusiva é o mesmo em que o país adota uma política de universalização de escolaridade do Ensino Fundamental. Também é o mesmo período em que as agências internacionais difundem as mudanças relativas às matrículas de alunos com deficiências nas escolas comuns ocorridas nos diferentes países nos anos anteriores. Mel Ainscow, consultor da UNESCO, apresenta um levantamento realizado pela UNESCO na década de 1980 que registrou que em 58 países, a organização da Educação Especial dava-se predominantemente em escolas especiais separadas, que atendiam um número reduzido de alunos (AINSCOW, 1995). A partir dessas informações, o relatório da UNESCO indicava que ante as: "proporções da demanda e os escassos recursos disponíveis, as necessidades de educação e formação da maioria das pessoas deficientes não pode satisfazer-se 
unicamente em escolas e centros especiais ${ }^{17 "}$ (UNESCO, 1988 apud AINSCOW, 1995, p.18). A partir dessa constatação, Ainscow afirma que,

[...] é necessário introduzir mudanças tanto nas escolas especiais como nas regulares [...] Há muitas indicações de que em um número elevado de países de todo o mundo a integração18 é um elemento central na organização da educação especial [...]. Esse projeto parece adequado para os países do Terceiro Mundo, dada a magnitude das necessidades e as inevitáveis limitações de recursos disponíveis (AINSCOW, 1995, p.18, tradução livre).

O documento da UNESCO de 1988 já anunciava as diretrizes propostas pela Declaração de Salamanca em 1994. Essas diretrizes foram incorporadas em documentos nacionais. A proposição de que "todas as crianças, sempre que possível, devem aprender juntas, independentemente de suas dificuldades e diferenças" (DECLARAÇÃO DE SALAMANCA, 1994) fazem parte do discurso em pauta nos documentos que difundem a Educação Inclusiva no Brasil, desde a década de 1990. Em diferentes documentos brasileiros, princípios dos direitos humanos são trazidos à tona e apresentados como "fundamentação filosófica" de documentos disseminados pelo Ministério da Educação. Trechos como os da Declaração de Viena (1993), como o exposto abaixo, são utilizados para justificar as medidas tomadas pelo Governo Brasileiro na condução da educação para as pessoas com deficiências:

[...] Deve-se dar atenção especial às pessoas portadoras de deficiências, visando a assegurar-lhes um tratamento não-discriminatório e eqüitativo no campo dos direitos humanos e liberdades fundamentais, garantindo sua plena participação em todos os aspectos da sociedade.

Todos os aspectos apresentados vão indicando uma forte relação entre agências internacionais e elaboração de políticas educacionais. Como já me referi anteriormente, no início dos anos 90 as agências multilaterais abriram-se para as demandas da promoção de direitos humanos e programas e ações foram propostos disseminando conceitos e posições. Nesse período, o termo inclusão passa a fazer parte do discurso educacional brasileiro. Um documento elaborado em 1994 no Governo de Itamar Franco, denominado "Tendências e Desafios da Educação Especial", ao relatar um projeto de capacitação de educadores, afirmava a importância da inclusão de alunos com deficiências na Escola Regular, da compreensão do conceito de inclusão, das oportunidades de aprendizagem na sala de aula regular e da necessidade de envolvimento dos pais. No governo subseqüente, de Fernando Henrique Cardoso, uma nova Lei de Diretrizes e Bases da Educação foi aprovada em 1996, trazendo preceitos importantes para a matrícula de alunos com deficiências nas escolas do país. Acordos foram assinados e muitos se transformam em leis no país, como é o caso da aprovação do Decreto n ${ }^{\circ} 3.956 / 01$, promulgando a Convenção Interamericana para a Eliminação de Todas as Formas

\footnotetext{
17 Tradução livre.

${ }^{18}$ É importante esclarecer que o autor utiliza, aqui, o termo integração, mas referindo-se a matrículas de alunos com deficiências em escolas comuns.
} 
KASSAR, M. C. M

de Discriminação contra as Pessoas Portadoras de Deficiência. No mesmo ano, a Resolução 02/2001 aprovou as Diretrizes Nacionais para a Educação Especial na Educação Básica.

O Governo de Luiz Inácio Lula da Silva continuou a difusão dos princípios de inclusão, inclusive adotando o termo em seus Planos Plurianuais (Plano Brasil de Todos: participação e inclusão - 2004-2007 e Plano Desenvolvimento com inclusão social e educação de qualidade - 2008-2011). Apresentada como prioridade nacional, a educação deveria promover a eqüidade, valorizar a diversidade e proporcionar a inclusão social, discurso coerente ao propagado pela Organização das Nações Unidas.

\section{CONSIDERAÇões Finais}

Iniciei este artigo apresentando um conceito de política pública que implica a existência do jogo de forças em uma sociedade em que essas forças possam ser expostas. No texto, ressaltei aspectos que considerei importantes em nossa história da educação e algumas relações possíveis entre e documentos internacionais e leis e diretrizes educacionais. Admitindo-se a existência de um papel determinado da educação no processo de globalização, até que ponto, tem-se autonomia nas decisões internas?

No jogo de forças para o estabelecimento de ações, outros atores sociais também entram em cena. Em 2001, um ofício oriundo da Procuradoria da República do Distrito Federal encaminhou ao Ministro de Estado da Educação da época, Paulo Renato, cópia de recomendação ao Conselho Nacional de Educação, que tinha por objeto a educação inclusiva, a partir do Parecer CNE/CEB 17/2001 e da Resolução CNE/CEB 02/2001. O ofício entendia que "tais documentos exarados pela Câmara de Educação Básica (CEB) apesar de corretos em suas considerações iniciais, apesar da defesa da educação inclusiva independentemente de raça, classe, gênero, sexo ou características individuais, ao definirem as políticas relativas ao atendimento especializado na rede regular, contrariam os princípios da igualdade e da nãodiscriminação ao admitirem currículos adaptados em escolas e salas especiais e conseqüentemente certos portadores de deficiência poderão ficar à margem do ensino regular, o que não atende aos mandamentos constitucionais" (MEC/CNE/ CEB, 2002). Após análise da documentação, o relator da Câmara de Educação Básica do Conselho Nacional de Educação entendeu que o Parecer CNE/CEB n ${ }^{\circ}$ 17/2001 e a Resolução CNE/CEB nº 02/2001 obedeceram à própria Constituição e à Lei de Diretrizes e Bases da Educação de 1996 e que "não encontrou antinomias com o texto constitucional, com textos infraconstitucionais pertinentes. Tampouco encontrou defeitos que desfigurem o preceito constitucional da igualdade, da eqüidade e da justiça" (idem).

Dois anos depois, em 2003, a Secretaria dos Ofícios de Tutela Coletiva de São Paulo enviou ao Conselho Nacional de Educação e à Câmara de Educação 
Básica outro ofício, com teor semelhante ao ofício anterior, dessa vez solicitando que o Conselho fizesse "adequações necessárias à Resolução CNE/CEB 2/2001 para que sejam cumpridas as disposições do Decreto 3.956, de 8 de outubro de 2001" (MEC/CNE/CEB, 2004). O ofício explica que o decreto decorre da assunção, pelo país, da Convenção Interamericana para a Eliminação de Todas as Formas de Discriminação Contra as Pessoas Portadoras de Deficiência, aprovada pelo Congresso Nacional por meio do Decreto Legislativo 198, de 13 de junho de 2001. Diante do assunto em questão, a relatora propôs incluir a referência ao Decreto Legislativo 198, de 13 de junho de 2001 no preâmbulo da Resolução e também como um artigo da Res. CNE/CEB 2/2001, nos seguintes termos: "Os sistemas de ensino atenderão ainda aos dispositivos do Decreto 3.956/2001, que promulga a Convenção Interamericana para a Eliminação de Todas as Formas de Discriminação contra as Pessoas Portadoras de Deficiência" (MEC/CNE/CEB, 2004). Outras alterações sugeridas pelo ofício não foram acatadas, como a transformação das escolas especiais em centros de atendimento educacional especializados.

As alterações não acatadas - a transformação de escolas especiais em centros de atendimento educacional especializados e a mudança da educação especial com a possibilidade de substituição à escolaridade comum, para apenas a possibilidade de complementação ou suplementação - são focos dos debates atuais no campo da Educação Especial. Desde 2003, documentos oriundos do Governo Federal passaram a anunciar a implantação do que se tem denominado de sistemas educacionais inclusivos. Refere-se a um sistema educacional formado de escolas que comportem toda e qualquer criança e que o atendimento educacional especializado seja apenas complementar ou suplementar à escolaridade comum. Diferentes programas foram lançados a partir dessa data, indicando a organização desse sistema inclusivo. A adoção dessas ações tem causado diferentes reações da sociedade civil. Por um lado, grupos que ganham apoio das instituições especializadas apontam a precariedade da implantação desse sistema inclusivo nesses termos. Como exemplo, há o movimento de alunos surdos, que participaram de um ato público em Brasília em maio de 2011. Segundo reportagem de um jornal gaúcho, o fechamento de algumas escolas de surdos desencadeou esta mobilização, além do anúncio de fechamento do ensino básico no Instituto Nacional de Educação dos Surdos e no Instituto Benjamin Constant (PROTESTO..., 2001). Essa informação também foi veiculada na revista da Federação Nacional de Educação e Integração dos Surdos - FENEIS, de junho-agosto do mesmo ano.

As instituições privadas de caráter assistencial também têm se mobilizado e externado preocupações com os atuais rumos da Educação Especial no país. Na página da Federação das APAES encontramos os dizeres:

A Apae é a favor de um processo de inclusão escolar gradativo (processual) e responsável, com o qual as escolas comuns sejam devidamente preparadas para o recebimento dos estudantes, que necessitam não apenas de recursos para acessibilidade física, mas, sobretudo de treinamento de professores, preparação dos alunos, dentre outras ações. Além disso, a Rede Apae defende o direito de escolha da pessoa com 
deficiência intelectual e de sua família sobre o local onde deseja estudar (grifos no original).

Por outro lado, representantes do movimento Inclusão Já e da Rede Inclusiva - Direitos Humanos no Brasil apresentou em julho de 2011 ao Ministro da Educação, Fernando Haddad, um Manifesto denominado Convenção sobre os Direitos das Pessoas com Deficiência - Cumpra-se!, defendendo a política de educação inclusiva atualmente em implantação pelo Ministério da Educação. O movimento também luta pela manutenção da redação dada pelo Ministério à meta $n^{\circ} 4$ do Plano Nacional de Educação (PNE) 2011-2020, que tramita na Câmara dos Deputados que pretende: "Universalizar, para a população de 4 a 17 anos, o atendimento escolar aos estudantes com deficiência, transtornos globais do desenvolvimento e altas habilidades ou superdotação na rede regular de ensino" (ENTIDADES..., 2011).

Toda essa movimentação demonstra a luta de diferentes setores na concreticidade da elaboração de políticas públicas, características de sociedades em que há a possibilidade de manifestação. É inegável o impacto dos acordos e compromissos internacionais na formulação de políticas, programas e ações. A própria concepção de direitos humanos é formatação de um ideário de homem, que corresponde historicamente à idéia ocidental-liberal de justiça e igualdade. No entanto, na complexidade da formulação das políticas públicas, as relações das interferências não são unilaterais e tampouco mecânicas. As manifestações relatadas acima indicam a capacidade coletiva de formulação de agendas públicas e a existência de estruturação das instituições políticas do país. Indica também a possibilidade de construir diferentes rumos para a Educação brasileira.

\section{REFERÊNCIAS}

AINSCOW, M. Necesidades especiales en el aula. Guía para la formación del profesorado. Paris: UNESCO; Madrid: NARCEA, 1995.

ARRUDA, E. E.; KASSAR, M. C. M.; SANTOS, M. M. Educação Especial: o custo do atendimento de uma pessoa com necessidades especiais em instituições pública estatal e não estatal, em MS, 2004. In: NERES, C. C.; LANCILLOTTI, S. S. P. (Org.). Educação especial em foco: questões contemporâneas. Campo Grande: Ed. UNIDERP, 2006. p.89-116.

BASBAUM, L. História Sincera da República. Das origens a 1889. 5. ed. São Paulo: AlfaOmega, 1975-76.

BAYER, H. Da integração escolar à educação inclusiva: implicações pedagógicas. In: BAPTISTA, C. R. (Org.). Inclusão e escolarização: múltiplas perspectivas. Porto Alegre: Mediação: 2006.

BRASIL, s/d, Diagnósticos educacionais. Brasil. 1872-1980. Disponível em: <http:/ / www.dominiopublico.gov.br/download/texto/me002066.pdf>. Acesso em: jul. 2011.

BRASIL. CNE/CEB. Diretrizes Nacionais de Educação Especial para a Educação Básica. Decreto 02 - Brasília, 11 de setembro de 2001.

BRASIL. Constituição Federal 1988. Brasília: Senado, 1988. 
Percursos de uma política brasileira de Educação Especial

BRASIL. II Plano Setorial da Educação e Cultura. Brasília: Departamento de Documentação e Divulgação, 1976.

BRASIL. MEC. Programa de recuperação de excedentes 1974/1979. Brasília, 1975. Disponível em: <http://www.dominiopublico.gov.br/download/texto/me001908.pdf>. Acesso em: jul. 2011.

BRASIL. Ministério da Educação e Cultura. Educação Especial no Brasil: síntese estatística. Brasília, 1984.

BRASIL. Ministério da Educação. Coordenação de Informações para o Planejamento. Sinopse estatística da Educação Especial. v.I, 1988. Brasília: MEC/CIP, 1991a.

BRASIL. Ministério da Educação. Coordenação de Informações para o Planejamento. Sinopse estatística da Educação Especial. v.II, 1988. Brasília: MEC/CIP, 1991b.

BRASIL. Ministério do Planejamento, Orçamento e Gestão. Secretaria de Planejamento e Investimentos Estratégicos. Plano Plurianual 2004-2007. Mensagem presidencial, 2003. Disponível em: <http//www.sigplan.gov.br/arquivos/portalppa/41_ (menspresanexo). pdf>. Acesso em: abr. 2010.

BRASIL. Plano Plurianual 2008-2011. v.I, 2007. Disponível em: <http//www. planejamento.gov.br/secretarias/upload/Arquivos/spi/plano_plurianual / PPA/081015_PPA_2008_mesPres.pdf>. Acesso em: abr. 2010.

BRASIL. Secretaria de Educação Especial. Tendências e Desafios da Educação Especial. Organizado por Eunice M. L. Soriano de Alencar. Brasília: SEESP, 1994.

BUENO, J. G. S. Educação Especial brasileira: integração/segregação do aluno diferente. São Paulo: EDUC: FAPESP, 2004.

COSTA (1868) In: Antologia de textos pedagógicos do século XIX português. Lisboa: Instituto Gulbenkian de Ciência, 1975. v.3.

DALE. Globalização e educação: demonstrando a existência de uma "cultura educacional mundial comum" ou localizando uma "agenda globalmente estruturada para a educação"? Educação e Sociedade, Campinas, v.25, n.87, p.423-460, 2004. Disponível em: $<$ http//www.cedes.unicamp.br>.

DECLARACION DE SALAMANCA. Marco de acción para las necesidades educativas especiales. Aprobada por la conferencia mundial sobre necesidades educativas especiales: acceso y calidad. Salamanca, España, 7- 10 de junio de 1994.

SÃO PAULO (Estado). Decreto 5.884 de 21 de abril de 1933. Institui o código de Educação do Estado de São Paulo. Revista de Educação, v.2, 1933.

DI GIOVANNI, G. As estruturas elementares das políticas públicas. Caderno de pesquisa, Campinas, n.82, 2009.

DRAIBE, S.; RIESCO, M. Estado de bienestar, desarrollo económico y ciudadanía: algunas liciones de la literatura contemporánea. Caderno de pesquisa, Campinas, n.77, 2006.

ENTIDADES de direitos humanos manifestam apoio à educação inclusiva. Disponível em: <http/ / www.inclusive.org.br/?p=20236>. Acesso em: jul. 2011.

FERREIRA, J. A exclusão da diferença. Piracicaba: Ed. Unimep, 1993. 
KASSAR, M. C. M.

FILHO, L. Introdução ao estuda da Escola Nova. Bases, sistemas e diretrizes da Pedagogia Contemporânea. 11. Ed. São Paulo: Melhoramentos, 1974.

FINNEMORE, M. International organizations as teachers of norms: The United Nations Educational, Scientific, and Culture Organization and science policy. International Organization, v.47, n.4, p.565-597, 1993. Disponível em: <http://www.fpvmv. umb. sk/ fpvmv_www/phprs/storage/File/ksp/GLUN/T_Finnemore_1993_IO_norms_ constructivism.pdf $>$. Acesso em: fev.2011.

GALLAGHER, J. J. Planejamento da educação especial no Brasil. In: PIRES, N. (Org.). Educação especial em foco. Rio de Janeiro: Centro Brasileiro de Pesquisas Educacionais, 1974.

JANNUZZI, G. A educação do deficiente no Brasil: dos primórdios ao início do século XXI. Campinas: Autores Associados, 2004.

. A luta pela educação do deficiente mental no Brasil. São Paulo: Cortez: Autores Associados, 1985.

. As políticas e os espaços para a criança excepcional. In: FREITAS, M. C. (Org.). História social da infância no Brasil. São Paulo: Cortez: USF, 1997.

KOERNER, A. O papel dos direitos humanos na política democrática: uma análise preliminar. Revista Brasileira de Ciências Sociais, v.18, n.53, p. 143-157, 2003. Disponível em: <http://www.scielo.br/pdf/rbcsoc/v18n53/18083.pdf>.

LAPLANE, A. L. F. A inclusão escolar na Inglaterra. In: MENDES, E.; ALMEIDA, M.A. (Org.). Das margens ao centro: perspectivas para as políticas e práticas educacionais no contexto da educação especial inclusiva. Araraquara: Junqueira e Marins, 2010.

LAPLANE, A. L. F. Uma análise das condições para a implementação de políticas de educação inclusiva no Brasil e na Inglaterra. Educação $\mathcal{E}$ Sociedade, v.27, p.689-715, 2006.

MAZZOTTA, M. Educação Especial no Brasil: História e políticas públicas. São Paulo: Cortez, 1996.

MEC/CNE/CEB. Parecer 11/2004. Consulta tendo em vista o artigo 58 da Lei 9.394/96LDB e a Resolução CNE/CEB 2/2001, que instituiu Diretrizes Nacionais para a Educação Especial na Educação Básica. Brasília, 2004.

MEC/CNE/CEB. Parecer 4/2002. Recomendação ao Conselho Nacional de Educação tendo por objeto a educação inclusiva de pessoas portadoras de deficiência. Brasília, 2002.

MENDES, E. G. A radicalização do debate sobre inclusão escolar no Brasil. Revista Brasileira de Educação, v.11, n.33, p.387-559, 2006.

MOURA, E. B. B. de. Infância operária e acidente do trabalho em São Paulo. In: DEL PRIORI, M. (Org.). História da criança no Brasil. São Paulo: Contexto, 1991.

NIRJE, B. How I came to formulate the Normalization principle. In: FLYNN, R. J.; LEMAY, R. A. (Org.). A quarter-century of normalization and Social Role Valorization: Evolution and impact. Ottawa: University of Ottawa Press, 1999.

ORTIZ GONZALEZ, M. C. Evolución histórica de la atención a las necesidades educativas especiales: una perspectiva desde la universidad. In: CONGRESO 
Percursos de uma política brasileira de Educação Especial

NACIONAL SOBRE UNIVERSIDAD Y DISCAPACIDAD, 1., 2005, Salamanca. Anais... Salamanca, 2005. p.11-14.

PEIXOTO, A. C. A reforma educacional Francisco Campo - Minas Gerais, Governo Presidente Antônio Carlos. 1981. Dissertação (Mestrado em Educação) - Universidade Federal de Minas Gerais, 1981.

PIRES, N. Educação especial em foco. Rio de Janeiro: Centro Brasileiro de Pesquisas Educacionais, 1974.

PROTESTO contra atual modelo de educação para surdos do MEC, 17/5/2011. Disponível em: <http:/ / www.diariodamanha.com/noticias.asp?a=view\&id=11351>. Acesso em: jul. 2011.

RIBEIRO, M. L. S. História da educação brasileira: a organização escolar. 2. ed. São Paulo: Cortez \& Moraes, 1979.

ROCHA, M. A. S. A educação do deficiente mental no estado de São Paulo (1843-1971). I. Boletim SAPERE AUDE, v. 15, n.22, 1979.

SAVIANI, D. Escola e democracia. Edição Comemorativa. Campinas: Autores Associados, 2008.

UNESCO. A educação no mundo. Vol. 1. O ensino de primeiro e segundo graus. Seleção de textos extraídos da obra L'éducation dans le monde. Tradução de Hilda de Almeida Guedes. v.3, 1963. São Paulo: Saraiva: Ed. da Universidade de São Paulo, 1982.

UNESCO. Convenção relativa à Luta contra a Discriminação no campo do Ensino, Adotada a 14 de dezembro de 1960, pela Conferência Geral da UNESCO, em sua $11^{\text {a }}$ sessão, reunida em Paris de 14 de novembro a 15 de dezembro de 1960, 2003.

UNESCO. Salamanca cinco años después. Una revisión de las actividades de UNESCO a la luz de la declaración y el marco de acción de salamanca. Adoptada en: la Conferencia Mundial sobre Necesidades Educativas Especiales: acceso y calidad. Sección de Necesidades Educativas Especiales Dirección de Educación Básica, 1999.

VEIGA, C.G. Escola pública para os negros e os pobres no Brasil: uma invenção imperial. Revista Brasileira de Educação, v.13, n.39, p.502-516, 2008.

Recebido em: 22/07/2011

Aceito em: 30/08/2011 